\title{
El papel de los medios de comunicación en la campaña electoral
}

\author{
María Holgado González \\ Profesora de Derecho Constitucional \\ Universidad Pablo de Olavide, Sevilla
}

\section{RESUMEN}

Los medios de comunicación desempeñan un papel fundamental en el funcionamiento del sistema democrático, especialmente durante la campaña electoral, proporcionando la información necesaria para que los ciudadanos ejerzan su derecho al voto de forma libre y racional. Algo que no escapa a los partidos políticos, que encuentran en los medios, sobre todo en la televisión, el cauce idóneo para hacer llegar a los ciudadanos su mensaje y dar a conocer a sus líderes. El Estado, en este punto, tiene que garantizar la igualdad de oportunidades de todas las formaciones que concurren a las elecciones, imponiendo la neutralidad y el respeto al pluralismo político en la información electoral.

Este artículo analiza, desde un punto de vista crítico, las leyes que regulan en nuestro país el acceso de los partidos a los medios (prohibición de contratar publicidad electoral, espacios gratuitos, etc.). Una regulación que, hasta la fecha, se ha basado más en la idea de la propaganda que en la de la confrontación política entre las distintas opciones. Por ello se reclama la fórmula del debate electoral como la mejor vía para que los ciudadanos conozcan las diferentes propuestas políticas y decidan mejor su voto.

\section{ABSTRACT}

Media play an essential role in the democratic system, especially during electoral campaign, because they provide citizens the indispensable information to perform the right to vote in a rational and really free way. Political parties know that, so they consider media (television above all) as the best means to communicate citizens their message and introduce their leaders. State must act in order to guarantee equal opportunities to political groups that are present at elections, and to survey neutrality and the respect of political pluralism in elections information.

This article analyses, since a critical point of view, statutes that regulate political parties' access to media (interdiction of electoral publicity, electoral TV free times, etc.) in our country.

This is a regulation that prefers propaganda to controversy between political leaders. Nevertheless we consider electoral debates are the best TV program for electorate to know several political proposals and decide their vote.

Palabras claves: Partidos políticos/Medios de comunicación/Campaña electoral/Elecciones/ Publicidad electoral/Debates electorales televisados/Espacios electorales gratuitos/ Libertad de información/Neutralidad.

Key words: Political parties/Media/Electoral campaign/Electorate/Elections/Electoral publicity/ Electoral TV debates/Free electoral advertising/Freedom of the press/Neutrality. 


\section{Introducción}

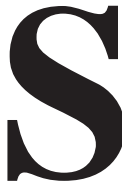

in medios de comunicación sería difícil de imaginar hoy día la democracia. La vida política, sin duda, se enfoca y desarrolla de cara a los mass media. No hay mitin o acto de partido, intervención parlamentaria, actuación de un miembro del Gobierno o declaración de algún representante de la oposición que no se realice sin tener presente su repercusión en la opinión pública. No es exagerado afirmar, por tanto, que, especialmente cuando se acercan las elecciones, los partidos y sus líderes, actúan condicionados por el posible "titular" del día siguiente. Y es que la influencia de los medios de comunicación, que alcanza su grado máximo tratándose de la televisión, y su relevancia como fuente de información política son innegables en la sociedad contemporánea. Hasta el punto de poder hablar, como Sartori, de telecracia, aludiendo con ello a que «la televisión condiciona fuertemente el proceso electoral, ya sea en la elección de los candidatos, bien en su modo de plantear la batalla electoral o en la forma de ayudar a vencer al vencedor» ${ }^{1}$.

\section{La regulación de los medios durante la campaña}

La presencia en los medios, especialmente en la televisión, constituye, sin lugar a dudas, la más importante de las formas que tienen los partidos políticos de dar a conocer su mensaje y solicitar el voto durante la campaña electoral, frente a otras más clásicas como la tradicional "pegada de carteles" o la celebración de mítines. De hecho, estas últimas se siguen llevando a cabo pero con una finalidad mediática, es decir, están concebidas para ser televisadas, o recogidas en imágenes o titulares de prensa que tienen un considerable efecto multiplicador del mensaje. El líder del partido ya no expone su programa político únicamente a los asistentes al mitin, sino que lo hace, sobre todo, dirigiéndose a los telespectadores del espacio informativo en el que se recogerá su intervención (es sabido que los líderes que intervienen en estos actos son avisados de la inmediata conexión en directo de un espacio informativo de televisión ${ }^{2}$ ).

Consciente del relevante papel que juegan los medios de comunicación en un momento tan crucial en cualquier sistema democrático, como es el de las elecciones, el legislador ha regulado minuciosamente algunos aspectos de su funcionamiento durante la campaña electoral, en la LOREG $^{3}$ y en las Leyes Orgánicas reguladoras de la publicidad electoral ${ }^{4}$, con la idea de garantizar el

1 Sartori, G., Partidos y sistemas de partidos, Alianza Editorial, Madrid, 1999, pág. 66.

2 Rallo Lombarte, A., "Debates electorales y televisión”, Revista de las Cortes Generales, núm. 44, 1998, pág. 67.

3 Ley Orgánica del Régimen Electoral General (LO 5/1985, de 19 de junio).

4 Ley Orgánica 10/1991 de 8 de abril, reguladora de la publicidad electoral en las emisoras municipales de radiodifusión sonora; LO 14/1995 de 22 de diciembre, reguladora de la publicidad electoral en las emisoras de televisión local por ondas terrestres; y Ley Orgánica 2/1988 de 3 de mayo, reguladora de la publicidad electoral en las emisoras de televisión privada. 
pluralismo político y la igualdad de oportunidades entre todas las formaciones políticas, de modo que la contienda electoral sea lo más justa posible.

Tan alta aspiración se procura lograr principalmente a través de dos medidas previstas en estas leyes: la prohibición de contratar publicidad electoral, de un lado, y la concesión de espacios televisados gratuitos a las principales fuerzas políticas, de otro. Es cierto que, en cambio, esta legislación ha eludido un aspecto tan esencial como es el de la acción informativa de los medios de comunicación durante las elecciones, olvidando prestar mayor atención a la información electoral propiamente dicha o regular, por ejemplo, la celebración de debates electorales televisados.

a) La prohibición de contratar publicidad electoral

La primera de estas medidas trata de evitar que los recursos económicos de los partidos condicionen la igualdad en el acceso a los medios de comunicación, de modo que los que terminen haciendo uso de la publicidad electoral televisiva y acaparen el espacio audiovisual durante la campaña electoral sean los partidos económicamente fuertes. Es evidente que no todas las formaciones políticas cuentan con los mismos ingresos, ni pueden, por tanto, emplear el mismo esfuerzo económico en hacer llegar a los electores su mensaje y su programa, a través de la propaganda. Y como es sabido, la realizada en la televisión es de las más caras, por lo que quedaría sólo al alcance de unos pocos partidos. Por esta razón, en nuestro país se ha optado por la solución de prohibir a todos ellos contratar publicidad en las cadenas de televisión tanto públicas como privadas. Así, la presencia de los partidos en este medio de comunicación durante la campaña electoral no se hace depender de la capacidad económica de los mismos. La publicidad en la prensa escrita y en las emisoras de radio privadas se permite, si bien, ha de quedar claro para los lectores y oyentes que se trata de publicidad, por lo que ha de identificarse como tal para garantizar la correcta información del elector. Además, se prohíbe a estos medios toda discriminación entre los distintos candidatos en cuanto a la inclusión, tarifas y ubicación de dichos espacios 5 . Teniendo presente, como es razonable pensar, que cuantos más medios económicos estén a disposición de una fuerza política, en mejores condiciones se hallará para vencer a las demás o para defender sus puntos de $v^{2} \operatorname{sta}^{6}$, con estas medidas se consigue, al menos en este aspecto, la igualdad de condiciones entre todas las formaciones que concurren a las elecciones.

Esta igualdad que nuestra Constitución garantiza (art. 14), obligando, además, a los poderes públicos a involucrarse para que no sea un simple enunciado

5 Art. 58 LOREG.

6 Lucas Murillo de la Cueva, P., «La financiación de los partidos políticos», en Anuario de Derecho Constitucional y Parlamentario, núm. 5, 1993, págs. 103-193. 
formal, sino que se traduzca en una real y efectiva igualdad de oportunidades, promoviendo las condiciones necesarias para ello y removiendo los obstáculos que impidan o dificulten su plenitud (art. 9), es absolutamente indispensable para asegurar unas elecciones justas y verdaderamente democráticas. Los ciudadanos, para ejercer con verdadera libertad su derecho al voto, han de poder elegir entre todas las opciones que democráticamente se presentan al electorado, y para ello éstas han de tener oportunidad de darse a conocer a través de medios que se encuentren al alcance de todos. Sólo así se garantiza el pluralismo político que está considerado como uno de los valores superiores de nuestro ordenamiento jurídico (art. 1 CE).

\section{b) Los espacios gratuitos}

La prohibición de contratar publicidad en el medio televisivo viene contrarrestada por el derecho a disponer de espacios gratuitos en las cadenas públicas ${ }^{7}$. No podía ser de otro modo puesto que el acceso de las formaciones políticas a los medios de comunicación de titularidad pública está garantizado constitucionalmente a los "grupos políticos significativos". En efecto, nuestra Constitución, siguiendo el ejemplo de la Constitución portuguesa ${ }^{8}$, dice así:

«La ley regulará la organización y el control parlamentario de los medios de comunicación social dependientes del Estado o de cualquier ente público y garantizará el acceso a dichos medios de los grupos sociales y políticos significativos, respetando el pluralismo de la sociedad y de las diversas lenguas de España»?.

Para poder acceder a los espacios gratuitos en las emisoras de radio y televisión de titularidad pública los partidos tienen que cumplir el requisito de haber presentado candidaturas en un número determinado de circunscripciones electorales, que varía en función del ámbito de las elecciones en cuestión (generales $^{10}$, municipales ${ }^{11}$, europeas ${ }^{12}$, autonómicas $\left.{ }^{13}\right)$. El acceso a los medios de comu-

7 Zaccaria lo ha definido como «una indemnización normativa frente a la expropiación del derecho de libertad de expresión» (Zaccaria, R, Radiotelevisione e costituzione, Milano, 1977).

8 El primer reconocimiento constitucional del derecho a acceder a los medios de comunicación se encuentra en la Constitución portuguesa de 2 de abril de 1976, cuyo art. 40.2 establece que «en época de elecciones los partidos políticos concurrentes tendrán derecho a períodos de emisión regulares y equitativos».

9 Art. 20.3 CE.

10 El 75 por 100 de las circunscripciones comprendidas en el ámbito de difusión del medio (art. 64.2 LOREG).

11 Municipios que representen el 50 por 100 de la población de las circunscripciones incluidas en el ámbito de difusión del medio (art. 188 LOREG).

12 Al ser una circunscripción única, todos los partidos que concurren a las elecciones tienen derecho a espacios gratuitos.

13 Se aplica supletoriamente lo dispuesto para las elecciones generales cuando la Comunidad Autónoma no haya dispuesto algo distinto en su legislación electoral.

14 Santolaya Machetti, P., Manual de procedimiento electoral, Madrid, Ministerio del Interior, 1995, pág. 99.

15 Pajares Montolío, E., La financiación de las elecciones, Congreso de los Diputados, Madrid, 1998, pág. 193. 
nicación queda asegurado, por tanto, a prácticamente todas las formaciones políticas, estén o no representadas en el Parlamento, evitando que la oferta electoral mostrada en los mass media se reduzca a los dos o tres partidos más significativos. Y ello contribuye en alguna medida a la movilidad del sistema de partidos, permitiendo a las formaciones nuevas o que no alcanzaron representación en elecciones anteriores, darse a conocer y difundir su mensaje a través de medios con tanta repercusión como son la radio y la televisión. Hay algunos autores que consideran, no obstante, que las actuales condiciones para beneficiarse de estos espacios gratuitos son extremadamente generosas por haber permitido a partidos ficticios utilizar estos espacios con fines distintos a los electorales, "produciendo con ello, al margen de un claro fraude de ley, una sobresaturación de tiempos de propaganda electoral, que acaban perjudicando a las auténticas candidaturas y en definitiva al conjunto del electorado"14. Por este motivo sugieren endurecer estos requisitos o exigir una fianza a los partidos que concurran a las elecciones, fianza que sería devuelta después de haber obtenido un número determinado de votos ${ }^{15}$. No obstante, no parece conveniente que para evitar su posible utilización fraudulenta se ponga obstáculos a quienes legítimamente pretenden hacer un correcto uso de ellas, teniendo en cuenta que exigir fianzas a pequeños partidos o a nacientes formaciones políticas los colocaría en una clara situación de desventaja frente a partidos ya consolidados que cuentan con suficientes fondos económicos.

El acceso a los medios de comunicación trata nuevamente de garantizar la igualdad de condiciones entre todas las formaciones políticas, igualdad que se traduce en proporcionalidad (tratamiento igual a los iguales y desigual a los desiguales), atendiendo al respaldo electoral en anteriores elecciones. Este también llamado por algunos "derecho de antena" 16 consiste en unos tiempos reservados en las emisoras de radio y televisión públicas que van desde los diez hasta los cuarenta y cinco minutos para cada partido, en función del número de votos que hayan obtenido en elecciones anteriores ${ }^{17}$. Las distintas Comunidades Autónomas han seguido un criterio similar a la hora de conceder espacios a los partidos en los medios de comunicación de titularidad pública dentro de su ámbito territorial de difusión (ya sean medios de la respectiva Comunidad, o medios nacionales en la programación regional).

La distribución de estos espacios gratuitos la lleva a cabo la Junta Electoral Central a la vista de la propuesta realizada por una Comisión de Radio y Televisión de la que forman parte representantes de los partidos políticos con escaño en el Congreso de los Diputados, participando con un voto ponderado ${ }^{18}$. Su tarea

16 García Llovet, E., "El derecho de antena y las campañas electorales”, Revista de Derecho Político, núm. 25, 1987.

17 Art. 64.1 LOREG.

18 Art. 65.3 LOREG. 
consiste en distribuir entre los distintos partidos los espacios gratuitos reservados en las emisoras de radio y televisión públicas para la emisión de mensajes electorales, y lo hace aplicando los criterios establecidos por la ley, y atendiendo a las preferencias de los partidos mayoritarios ${ }^{19}$. La Junta Electoral Central es el órgano decisor y puede aceptar la propuesta de la Comisión de Radio y Televisión, modificarla en los aspectos que estime oportunos o resolver las discrepancias habidas en su seno. Tratándose de la programación regional o local de estos medios públicos, la Junta Electoral Central puede, y, de hecho, así viene haciéndolo, delegar su competencia en las Juntas Electorales Provinciales que nombrará una Comisión, con las mismas funciones y composición, en el ámbito territorial de que se trate.

\section{La exigencia de neutralidad}

Como decíamos al principio, en este terreno la legislación española adolece de una visión de los medios de comunicación poco acorde con su función informativa. Al prohibir la contratación de publicidad electoral e imponer espacios gratuitos para los partidos en las emisoras de radio y televisión públicas, estas leyes parecen sólo tener en cuenta a los medios de comunicación como instrumento o lugar para la propaganda política. Dicho de otro modo, se acercan más a la idea del "consumidor al que se trata de manipular que a la del ciudadano al que hay que informar"

Pero, ¿qué ocurre con la programación informativa? No nos referimos ya a los tiempos concedidos a los partidos de forma gratuita para que expongan y den a conocer con total libertad su programa y a su candidato ${ }^{21}$, sino a la información sobre elecciones que es elaborada por los propios medios de comunicación y que «goza de mayor capacidad de influencia en la formación de la opinión pública en tanto se presume su imparcialidad, objetividad y veracidad» ${ }^{22}$. A nadie se oculta que mientras que el ciudadano apenas repara en los espacios electorales cedidos obligatoriamente a los partidos, sí muestra mayor interés por la infamación electoral recogida en los telediarios y en otros programas.

Pues bien, la única referencia a la información política durante la campaña electoral que encontramos en las leyes es la que exige a las emisoras de radio y

19 Art. 65.2 LOREG.

20 Arnaldo Alcubilla, E., "Procesos electorales y opinión pública”, Revista de las Cortes Generales, núm. 34, 1995, pág. 175.

21 Con el requisito, eso sí, de pedir el voto a los electores; por lo que se le ha negado a las formaciones políticas que propugnen en ellos la abstención, como fue el caso de EH que pretendía utilizar los espacios con el lema "En el camino de la autodeterminación: la abstención" (Junta Electoral Central, sesión de 21 de febrero de 2000).

22 Rallo Lombarte, A., «Debates electorales y televisión», op. cit., pág. 67. 
televisión respetar los principios de neutralidad y pluralismo político ${ }^{23}$. Así, cualquier comportamiento que se aparte de dicha neutralidad tanto en las cadenas públicas como privadas puede ser recurrido ante la Junta Electoral ${ }^{24}$.

El principio de neutralidad informativa en los medios de comunicación de titularidad pública, esencial para el normal desarrollo de la campaña electoral, se recoge en el Estatuto de la Radio y la Televisión como uno de los principios inspiradores de su actividad ("la objetividad, veracidad e imparcialidad de las informaciones" ${ }^{25}$ ). Resulta, por otra parte, evidente que los medios de comunicación de titularidad pública deben realizar una adecuada cobertura informativa de la campaña electoral, dada la relevancia pública de las elecciones, desde el punto de vista del derecho de la sociedad a recibir información ${ }^{26}$.

El sometimiento de las emisoras de televisión privadas a los mismos límites de neutralidad y objetividad que las públicas durante la campaña electoral podría suscitar dudas acerca de su constitucionalidad ${ }^{27}$. ¿Cómo puede el Estado intervenir en el modo en el que se emite una información sobre elecciones? ¿Hasta qué punto puede limitar el ejercicio de la libertad de información, exigiendo esa neutralidad?

Estas dudas de inconstitucionalidad revisten más fundamento tratándose de un derecho que trasciende al simple ejercicio individual por parte del profesional, porque, como es sabido, las libertades de expresión e información contribuyen a la formación de una opinión pública libre, sin la que sería inconcebible el propio sistema democrático. Como ha reconocido el Tribunal Constitucional, las libertades de expresión e información constituyen "garantía de la opinión pública libre, que es una institución ligada de manera inescindible al pluralismo político, valor esencial del Estado democrático, estando estas libertades dotadas por ello de una eficacia que trasciende a la común y propia de los demás derechos fundamentales"28.

Ha de existir, por tanto, una causa jurídica lo suficientemente relevante como para justificar la limitación de la libertad de información consistente en exigir neutralidad en campaña electoral tanto a los medios públicos como privados. Y esa causa legitimadora es precisamente el ejercicio por los ciudadanos del

23 Art. 66 LOREG y leyes sobre publicidad electoral en emisoras de televisión privadas anteriormente citadas. El art. 23 del Estatuto de la Radio y la Televisión, en relación con la programación, nos remite a ellas al disponer que "Durante las campañas electorales se aplicará el régimen especial que prevean las normas electorales. Su aplicación y control se defieren a la Junta Electoral Central, que cumplirá su cometido a través del Consejo de Administración y del Director General”.

24 Instrucción de la Junta Electoral Central de 13 de septiembre de 1999.

25 Art. 4 a) del Estatuto de la Radio y la Televisión, Ley 4/1980, de 10 de enero.

26 García Llovet, E., "El derecho de antena y las campañas electorales", op. cit.

27 Martínez Sospedra, lo considera difícilmente compatible con el art. 20 CE. Vid. Martínez Sospedra, M., "La financiación de los partidos políticos. Ensayo de aproximación", Cuadernos Constitucionales de la Cátedra Fadrique Furió Ceriol, núm. 11/12, 1995, pág. 29.

28 STC 121/1989, de 3 de julio, FJ. $2^{\circ}$. Vid. por todas STC 6/1981, de 16 de marzo, FJ. $3^{\circ}$, STC 104/1986, de 17 de julio FJ. $5^{\circ}$, STC 165/1987, de 27 de octubre, FJ. $10^{\circ}$ y STC 107/1988, de 8 de junio, FJ. $2^{\circ}$. 
derecho al voto, que ha de ser, como dice la Constitución (art. 68.1), universal, igual, directo, secreto y además libre. Libertad que no se garantiza únicamente por la ausencia de cualquier tipo de presión o coacción en su ejercicio, sino que exige que el elector disponga de la información necesaria acerca de la oferta electoral (partidos que concurren a las elecciones, candidatos, programas de gobierno, etc.).

Si las libertades de expresión e información son indispensables en una sociedad democrática, por cuanto permiten formar una opinión pública libre, el derecho al sufragio es, como dice el Tribunal Constitucional, "nervio y sustento de la democracia" 29 , puesto que a través del mismo se logra la manifestación de la voluntad popular. Por ello, el Estado ha de velar por que los ciudadanos puedan tener los elementos necesarios para emitir su voto de manera racional tras haber recibido de forma apropiada la información referida a su entorno social y político así como a las opciones políticas existentes. Una información que, además de veraz, ha de ser completa, sin dejar fuera a ninguna de las formaciones políticas que concurren a las elecciones, y ofrecida con objetividad e imparcialidad. Tal limitación entraría por tanto dentro de la previsión constitucional según la cual las libertades de expresión e información "tienen su límite en el respeto a los derechos reconocidos en este Título" (art. 20.4 CE), a saber, el derecho a participar en los asuntos públicos y a acceder en condiciones de igualdad a las funciones y cargos públicos (art. $23 \mathrm{CE}$ ). Igualdad que, de nuevo, no ha de entenderse en un sentido mecánico, empleando la expresión del Tribunal Supremo, sino como proporcionalidad, esto es, "atendiendo a la representatividad adquirida en anteriores contiendas electorales" $"$. Ahora bien, los tiempos en la información electoral no tienen que ser una proyección exacta de los espacios gratuitos, porque no estamos ante propaganda electoral sino ante programas de naturaleza informativa, y "la determinación de su contenido y realización corresponde a empresas de gestión de los servicios de Radio y Televisión"31. De lo contrario, se estaría vulnerando la libertad de información del medio, que es el que ha de determinar qué hechos en campaña electoral son noticiables. Cuestión distinta es que finalmente la presión ejercida por los partidos que están representados en los Consejos de Administración de los Entes Públicos termine trasladando el mismo esquema de los espacios gratuitos a la información electoral.

Ésta es, además, una exigencia generalizada en los países europeos, donde se admiten sin ningún problema las limitaciones impuestas a los medios de comunicación, en cuanto son un instrumento para asegurar la igualdad de todos los participantes en el proceso electoral y la libertad del derecho de voto ${ }^{32}$. Así,

29 STC 24/1990, de 15 de febrero, FJ. $2^{\circ}$.

30 STS de 13 de febrero de 1996.

31 García Llovet, E., "El derecho de antena y las campañas electorales", op. cit., p. 172.

32 Rolla, G., "La reforma electoral en Italia", en Pau i Vall, F. (coord.), Parlamento y Sistema electoral, VI Jornadas de la Asociación Española de Letrados de Parlamentos, Aranzadi, 1999, págs. 378 y ss. 
encontramos la exigencia de espacios iguales a todos los partidos durante el período de la campaña electoral o la prohibición de transmitir mensajes publicitarios en estos medios durante los días previos a las elecciones (Italia) o el sometimiento de las emisoras de radio y televisión privadas a las recomendaciones del Consejo Superior de lo Audiovisual, debiendo respetar un equilibrio entre todos los partidos políticos en la emisión de la información relativa a las elecciones (Francia).

\section{Los debates electorales}

Junto a los espacios de información electoral que se insertan en los propios telediarios, y a los que, como acabamos de señalar, resulta de aplicación la exigencia de neutralidad, encontramos el formato televisivo de los debates electorales, que inauguraron con éxito Richard Nixon y John Kennedy en 1960 y que se han convertido en una práctica generalizada en buena parte de los países democráticos. En España, sin embargo, las leyes guardan un absoluto silencio en este aspecto; todo lo contrario a lo que sucede con la doctrina, que desde hace ya algún tiempo, viene reclamando su regulación y celebración, por considerarlos un medio idóneo para que del enfrentamiento entre los distintos candidatos y de la exposición del contenido de sus programas, el elector obtenga mejor la información necesaria para tomar la decisión que estime más conveniente, constituyendo «un expediente mucho más eficaz para formar la opinión pública» ${ }^{33}$.

Como ha escrito Artemi Rallo, «resulta indudable que los debates electorales constituyen el instrumento por excelencia de una idea constitucionalmente correcta de campaña electoral basada en la concurrencia no sólo formal sino cualitativa o material, en el contraste entre las diversas opciones electorales en términos de discusión, en el debate frente a la propaganda, en el diálogo frente al monólogo» ${ }^{34}$. La misma idea la destacaba González Encinar, con ocasión de las pasadas elecciones generales en las que no se llegó a celebrar ningún debate:

«El ciudadano, que luego como elector habrá de emitir su juicio sobre los distintos candidatos, necesita, como cualquier otro juez, que las partes confronten antes, directa y abiertamente, sus respectivas posiciones. Sólo así podrán los electores ejercer su derecho al voto con suficiente conocimiento de causa y de personas, habiendo visto a los candidatos en el ejercicio de la actividad esencial y definitoria de la democracia, el libre, abierto y pacífico debate de las ideas. Y por eso se celebran debates electorales en todos los países del mundo civilizado, menos en España. En realidad, si bien se mira, las elecciones que se celebran sin un previo debate público entre los candidatos más que elecciones democráticas son elecciones

33 Arnaldo Alcubilla, E., «Procesos electorales y opinión pública», op. cit., pág. 176.

34 Rallo Lombarte, A., «Debates electorales y televisión», op. cit., pág. 65. 
oclocráticas, o, para ser más exactos, son una prueba evidente de que la democracia degenera, tiende a la oclocracia» ${ }^{35}$.

$\mathrm{Y}$ es que, aunque parece que los actores políticos prefieren la propaganda al debate político (como se refleja en unas leyes que, al fin y al cabo, son obra de los partidos políticos representados en el Parlamento, destinatarios a su vez de las mismas), "la simplificación de los mensajes al contraste vivo de las opiniones por el potencial riesgo que su exposición comporta" 36 , no hay duda, a tenor de los índices de audiencia, de que los ciudadanos siguen con más atención los debates, estos espacios de confrontación, que presentan un formato más atractivo, y que se ajustan mejor a lo que debe entenderse por campaña electoral, esto es, la libre comunicación de ideas de los distintos candidatos que concurren a las elecciones ${ }^{37}$.

A pesar de no estar regulados en la LOREG, este tipo de debates se ha celebrado, sobre todo en los medios de comunicación de titularidad privada, y ha sido la Junta Electoral Central la que ha ido concretando su régimen jurídico, por ser la encargada de velar por el cumplimiento de los principios de neutralidad y pluralismo, como hemos señalado anteriormente ${ }^{38}$. Resulta, cuando menos, paradójico, que no hayan sido los medios de comunicación estatales los encargados de asumir y consolidar esta práctica, ya que, tratándose de un servicio público esencial $^{39}$, son la sede más apropiada para informar a los ciudadanos de las distintas opciones políticas que se presentan a las elecciones y someterlas al debate y al contraste. No hay que olvidar que el Estado tiene el deber de velar por el correcto funcionamiento del sistema democrático, que pasa por garantizar el ejercicio del derecho al sufragio en condiciones de libertad e igualdad, y para ello los ciudadanos han de poder acceder a una información veraz, neutral, completa y que respete el pluralismo político. De ahí que algunos autores ${ }^{40}$ insistan en la necesidad de que los debates electorales se realicen en los medios de comunicación de titularidad pública ${ }^{41}$, siguiendo el ejemplo del Ente Público de Radio Televisión de Andalucía en las elecciones autonómicas del 12 de junio de 1994.

De acuerdo con las directrices de la Junta Electoral, hay que entender que la LOREG ni prohíbe ni tampoco obliga a celebrar este tipo de programas pero, si la dirección del medio en cuestión, que es a quien corresponde decidir la

35 González Encinar, J. J., «Elecciones sin debates», en El País de 2 de marzo de 2000.

36 Arnaldo Alcubilla, E., «Procesos electorales y opinión pública”, op. cit., pág. 178.

37 Ibíd.

38 Acuerdos de la Junta Electoral Central de 22 de octubre de 1982, 29 de mayo de 1987, 3 de octubre de 1989, 16 de abril y 2 de junio de 1993 y 7 de junio de 1994.

39 Como establece el art. 1.2 del Estatuto de la Radio y la Televisión, Ley 4/1980, de 10 de enero.

40 Arnaldo Alcubilla, E., «Procesos electorales y opinión pública», op. cit., pág. 177.

41 Sin olvidar la contribución de esta medida a la reducción del gasto electoral de las formaciones políticas, ya que "limitaría muy probablemente la utilización de medios de publicidad de alto coste y dudosa eficacia" (Del Castillo, P., "Financiación de los partidos políticos: la reforma necesaria", en González Encinar, J. J. (coord.), Derecho de partidos, Espasa Universidad, Madrid, 1992, pág. 168. 
programación sin que la Administración electoral pueda sustituirla en esta función, decide llevarlos a cabo tendrán derecho a participar en los debates todas las formaciones políticas que concurran a las elecciones y ostenten representación parlamentaria, cuando así lo soliciten (puesto que se ha de respetar el pluralismo político y social y la neutralidad informativa). Ello no impide la existencia de debates bilaterales si se compensa la ausencia del resto de los partidos dándoles ocasión de participar en otros debates o cubriendo ampliamente la información de sus actos políticos.

Ésta es además la doctrina del Tribunal Supremo en la única sentencia sobre debates electorales dictada hasta la fecha, donde considera que los principios de igualdad, pluralismo y neutralidad informativas quedan garantizados tanto mediante debates bilaterales entre líderes de los partidos con mayor representación parlamentaria como a través de debates plurilaterales. Esta sentencia fue dictada con ocasión del recurso planteado por Izquierda Unida contra el Acuerdo de la Junta Electoral Central de 21 de mayo de 1993 que autorizó la celebración de los debates bilaterales entre Aznar y González en las emisoras de televisión privadas durante la campaña de las elecciones de 6 de junio de 1993. Según el Tribunal Supremo, no cabe impedir la celebración de debates electorales televisivos cuando exista acuerdo entre los partidos y los medios de comunicación y siempre que, respetando el principio de proporcionalidad, se conceda de la mejor forma posible a las demás fuerzas políticas similar oportunidad (o lo que es lo mismo, siempre que se haga una «oferta igual» al resto de partidos) sin que en ningún caso se pueda «imponer un determinado formato informativo, que puede invadir la libertad del medio de configurar técnicamente esos formatos ${ }^{42}$.

Así las cosas, aunque la celebración de debates en los que participen todas las formaciones políticas que se presentan a las elecciones parece la opción más justa, se ha terminado teniendo en cuenta que, empleando las palabras de Pérez Royo, «la fórmula del enfrentamiento directo entre los dos candidatos de los dos partidos que tienen la posibilidad real de formar gobierno es insustituible para que los ciudadanos puedan formarse una opinión sobre el programa con base en el cual va a ser dirigido el país o la comunidad autónoma y sobre la confianza que le merece la persona que va a ser portadora de dicho programa ${ }^{43}$. En tal sentido se manifiestan los esclarecedores resultados del trabajo realizado por Wert con motivo de las elecciones de 1993, en las que se llevaron a cabo los debates bilaterales Aznar-González, que congregaron aproximadamente a un tercio del censo electoral en audiencia media ${ }^{44}$.

42 STS de 13 de febrero de 1996.

43 Pérez Royo, J., «Debates electorales», El País, Andalucía, de 3 de marzo de 2000, pág. 2.

44 Wert, J. I., «Perspectivas de reforma del régimen electoral: campañas, medios de comunicación y encuestas electorales» en VV.AA.. La reforma del régimen electoral, Centro de Estudios Constitucionales, Madrid, 1994, pág. 95. 
Con independencia de que la celebración de estos debates influya o no de manera determinante en el sentido del voto de los ciudadanos, lo que sí parece comprobado es que, al menos, con este tipo de programas los medios de comunicación logran movilizar al electorado, fomentando la participación en las elecciones, algo, sin duda, saludable en todo sistema democrático y que es un objetivo en el que deben poner su empeño los poderes públicos, como ordena la Constitución (art. 9.2) ${ }^{45}$.

Como ha señalado el Tribunal Constitucional, "la importancia que el derecho de sufragio tiene en el sistema democrático justifica que los poderes públicos traten de favorecer la participación" 46 y no es una medida deseable sino que además "constituye mandato constitucional de los poderes públicos facilitar la participación de los ciudadanos en la vida política, social y cultural" ${ }^{47}$, lo que deben hacer garantizando que el ejercicio de este derecho se sustente en la optimización de los medios informativos/formativos de la opinión pública electo$\mathrm{ral}^{48}$.

\section{Reflexión final}

De todo lo hasta aquí expuesto se desprende una idea principal: los medios de comunicación ejercen una notable influencia sobre la ciudadanía, que no desprecian los partidos políticos durante la campaña electoral, de ahí que el Estado haya de velar por que no interfiera en la igualdad de oportunidades entre todas las formaciones políticas que concurren a las elecciones. Para ello, como hemos visto, las leyes electorales tratan de facilitar el acceso de los partidos a los medios, especialmente al de la televisión, reconociendo que constituye un cauce idóneo, dada su inmediatez y accesibilidad, para dar a conocer a los ciudadanos las distintas opciones políticas existentes.

Dicho esto, habría que objetar que la actual regulación de los medios durante la campaña electoral parece estar presidida por una idea que se aproxima más a la propaganda que al debate (de hecho, se limita a prohibir la contratación de publicidad y a ceder espacios gratuitos), ignorando que el ciudadano muestra un mayor interés por los programas de contenido informativo y, especialmente, por aquellos en los que se confrontan las formaciones políticas. Lamentablemente, en nuestro país no se ha consolidado la práctica, generalizada en muchos sistemas democráticos, de celebrar debates televisados entre los principales líderes políticos que se presentan a las elecciones. Y esta ausencia de debates se debe en gran

45 Y como ha recordado el Tribunal Constitucional: "a los poderes públicos corresponde favorecer el ejercicio del sufragio" (ATC 346/1991, de 15 de noviembre)

46 STC 189/1993, de 14 de junio, FJ. 5.

47 STC 208/1989, de 14 de diciembre, FJ. $3^{\circ}$ y ATC de 346/1991, de 15 de noviembre.

48 Rallo Lombarte, A., «Debates electorales y televisión», op. cit., p. 81. 
medida a que los candidatos (casi siempre el del partido del Gobierno) se resisten a exponerse al riesgo que conlleva todo enfrentamiento dialéctico con un adversario. Los partidos han optado, en la mayoría de las ocasiones, por un modelo de campaña basado en el lema de que "una imagen vale más que mil palabras", simplificando el contenido del mensaje político, que queda prácticamente reducido a la imagen del líder y al eslogan electoral. Como ha señalado Porras Nadales, en la era que vivimos la intervención de los grandes medios de comunicación ha supuesto "una reducción progresiva en el discurso de los líderes y en los contenidos racionales o ideológicos del mismo"49. Deberían, en cambio, aprovecharse los aspectos positivos de su utilización, en función de su indudable contribución al acercamiento de las formaciones políticas a los ciudadanos y a una mayor "visualización" y "transparencia" del proceso de toma de decisiones políticas, tradicionalmente alejado de los ojos de la sociedad ${ }^{50}$. Éste es el sentido con el que el actual Presidente del Tribunal Constitucional, Jiménez de Parga, emplea el término "televización (sic) de lo público", cuando señala que "la televisión... moviliza las voluntades" y "formaliza y potencia el ejercicio de los poderes en la actual sociedad" dando "presencia, talla y figura, a las instituciones"

De otro lado, sería conveniente evitar que la información que se ofrece en el medio televisivo consista, en la práctica, en una reproducción o reflejo de los espacios electorales cedidos gratuitamente a los partidos. La información que, hoy por hoy, se emite sobre la campaña electoral, especialmente en los medios públicos, no deja de ser sino tiempos de propaganda en beneficio de los partidos (como ha llegado incluso a reconocer el Tribunal Supremo ${ }^{52}$ ). Y ello se debe, en gran medida, a la presión ejercida por los partidos, representados en los Consejos de Administración de los Entes Públicos de la Radio y Televisión. Se echa en falta una información electoral menos encorsetada por la medición de los tiempos dedicados y por el actual formato consistente en dar simplemente paso a la voz e imágenes de los candidatos arengando a sus simpatizantes en los distintos mítines.

Reconociendo la dificultad de alcanzar el justo equilibrio entre la exigencia de neutralidad y respeto al pluralismo político que los medios han de guardar, de un lado, y el ejercicio de la libertad de información, de otro, no cabe duda de que habría que avanzar hacia su consecución. Lo que requiere una mayor voluntad por parte de las fuerzas políticas y un mayor grado de confianza en los profesionales

49 Porras Nadales, A., Representación y democracia avanzada, Cuadernos y debates, núm. 50, Centro de Estudios Constitucionales, Madrid, 1994, págs. 75-76.

50 Ibid.

51 Jiménez de Parga, M., "El Parlamento en el siglo XXI", en ABC del 26 de junio de 2002. Vid. también, del mismo autor, "Televización de lo público y democracia”, en ABC del 20 de febrero de 1996.

52 «No puede desconocerse que aunque el ofrecimiento de espacios informativos a los contendientes electorales tiene la caracterización de información, visto desde el medio de comunicación televisión, para los contendientes electorales que concurren a ellos representa una oportunidad de propaganda de sus propios programas y ofertas" (STS de 13 de febrero de 1996). 
de los medios de comunicación, que han de ser y son los primeros interesados en ejercer su labor periodística con el rigor que el electorado merece y que exige el derecho a la información como sustento de la democracia. Sería necesaria una mayor flexibilidad en la información electoral. Habría de ser el periodista el que, con la diligencia del profesional que ejerce la libertad de informar verazmente, decida qué hechos revisten la condición de noticiables e informar sobre ellos sin tener que ajustarse en su actuación a directrices, expresas o implícitas, de los partidos políticos representados en los citados Consejos de Administración. Porque una cosa es que se controle el adecuado reflejo en el medio televisivo de la pluralidad de opciones políticas entre las que los ciudadanos han de elegir con su voto y otra muy distinta que los espacios de información electoral se conviertan, como viene siendo la tónica, en una reiteración de los espacios de propaganda. Porque para la propaganda ya se les ceden tiempos a los partidos; ha de ser ya la hora de que la información electoral cumpla con su verdadero cometido: el de informar. 